\title{
Comparisons of health-related quality of life among surgery and radiotherapy for localized prostate cancer: a systematic review and meta-analysis
}

\author{
Cheng Chen ${ }^{1, *}$, Zhen Chen ${ }^{1, *}$, Kun Wang ${ }^{1}$, Linkun Hu${ }^{2}$, Renfang Xu ${ }^{1}$ and Xiaozhou \\ $\mathrm{He}^{1}$ \\ ${ }^{1}$ Department of Urology, The Third Affiliated Hospital of Soochow University, Changzhou, Jiangsu, P.R. China \\ ${ }^{2}$ Department of Urology, The First Affiliated Hospital of Soochow University, Suzhou, Jiangsu, P.R. China \\ *These authors contributed equally to this work \\ Correspondence to: Renfang Xu, email: xrfmnwk@163.com \\ Xiaozhou He, email: hxzmnwk@163.com \\ Keywords: prostatic neoplasms, prostatectomy, radiotherapy, quality of life
}

Received: August 21, $2017 \quad$ Accepted: September 22, $2017 \quad$ Published: October 05, 2017

Copyright: Chen et al. This is an open-access article distributed under the terms of the Creative Commons Attribution License 3.0 (CC BY 3.0), which permits unrestricted use, distribution, and reproduction in any medium, provided the original author and source are credited.

\section{ABSTRACT}

The objective of this study is to compare health-related quality of life (QOL) outcomes between radical prostatectomy (RP) and external beam radiation therapy (EBRT) for localized prostate cancer. PubMed, EMBASE, the Cochrane Library and Web of Science (to July 2017) were searched. Pooled analysis of each domain-specific score was calculated in relevant studies, and its change with follow-up time was explored by sub-group analysis. A total of six studies containing 4423 patients were included. Men underwent RP was associated with worse urinary and sexual domain score than EBRT (standardized mean difference $(S M D)=-0.59,-0.58 ; 95 \%$ confidence interval $(C I)=-0.73$ to $-0.45,-0.72$ to -0.44$)$. In contrast, EBRT group had lower bowel domain score than RP group (SMD $=0.42,95 \% \mathrm{CI}=0.33$ to 0.52 ). The sub-group analysis revealed the most severe urinary and sexual QOL in RP as well as bowel QOL in EBRT group all happened in the first month post operation. The different performance of two treatments in three QOL domains diminished afterwards. Healthrelated QOL should be considered comprehensively when planning follow-up for men after RP or EBRT for localized prostate cancer.

\section{INTRODUCTION}

Localized prostate cancer is classified by European Association of Urology (EAU) 2016 as in men with stage T1/T2, Nx/N0 and M0 [1] who are usually offered radical prostatectomy (RP), external beam radiation therapy (EBRT) and other treatments such as active surveillance, observation and brachytherapy. However, the optimal treatment of clinically localized prostate cancer remains controversial.

Health-related quality of life (QOL) is an increasingly important end-point in localized prostate cancer which was mostly measured using the Expanded Prostate Cancer Index Composite Instrument (EPIC) $[2,3]$. Randomized controlled trials (RCTs) [4-7], systematic reviews and meta-analysis [8-10] published so far have focused particularly on clinical oncological outcomes such as overall and cancer-specific survival, with little attention to patient-reported outcomes like health-related QOL. So we conduct this systematic literature review and meta-analysis of QOL outcomes reported by men after RP and EBRT for localized prostate cancer to compare the difference in the extent and duration of impaired QOL between the two treatments.

\section{RESULTS}

Included literature and related information

A total of 985 papers were obtained, and six of them were finally included according to the inclusion criteria [11-16]. See Figure 1 for the literature search process. Included literature covered a total of 4423 patients. Among 
them, 2615 men underwent RP and 1808 with EBRT. The follow-up time was one month to 15 years. The quality scores of the studies according to the Newcastle-Ottawa scale varied from 4 to 7 , with a mean of 6 . All studies were incorporated into the subsequent analysis. See Table 1 for literature information.

\section{Urinary quality of life}

Five studies [12-16] reported urinary quality of life in the analysis, including 22 comparisons at different follow-up time (Figure 2). Generally, patients undergoing RP had lower urinary domain scores than men undergoing EBRT (SMD = $-0.59 ; 95 \% \mathrm{CI}=-0.73$ to -0.45 ) (Supplementary Table 1 ). In sub-group analysis, compare to EBRT group, RP group had the lowest urinary domain scores in the first month $(\mathrm{SMD}=-2.62 ; 95 \% \mathrm{CI}=-2.97$ to -2.27$)$ and experienced $\mathrm{a}$ sharp increase in the following two months ( $\mathrm{SMD}=-0.81$; $95 \%$ CI $=-1.04$ to -0.59 ) (Supplementary Table 1). The gap between RP and EBRT was narrowing over the years and only minimal difference existed in the 15 th year $(\mathrm{SMD}=$ $-0.31 ; 95 \% \mathrm{CI}=-0.45$ to -0.17 ) (Figure 5).

\section{Sexual quality of life}

Six studies [11-16] reported sexual quality of life in the analysis, including 26 comparisons at different time points follow-up (Figure 3). Generally, patients undergoing RP had lower sexual domain scores than men undergoing EBRT $(\mathrm{SMD}=-0.58 ; 95 \% \mathrm{CI}=-0.72$ to -0.44) (Supplementary Table 1). In sub-group analysis, compare to EBRT group, RP group had the lowest sexual domain scores in the first month (SMD $=-3.60 ; 95 \%$ CI $=-4.35$ to -2.85$)$ and experienced a sharp increase in the

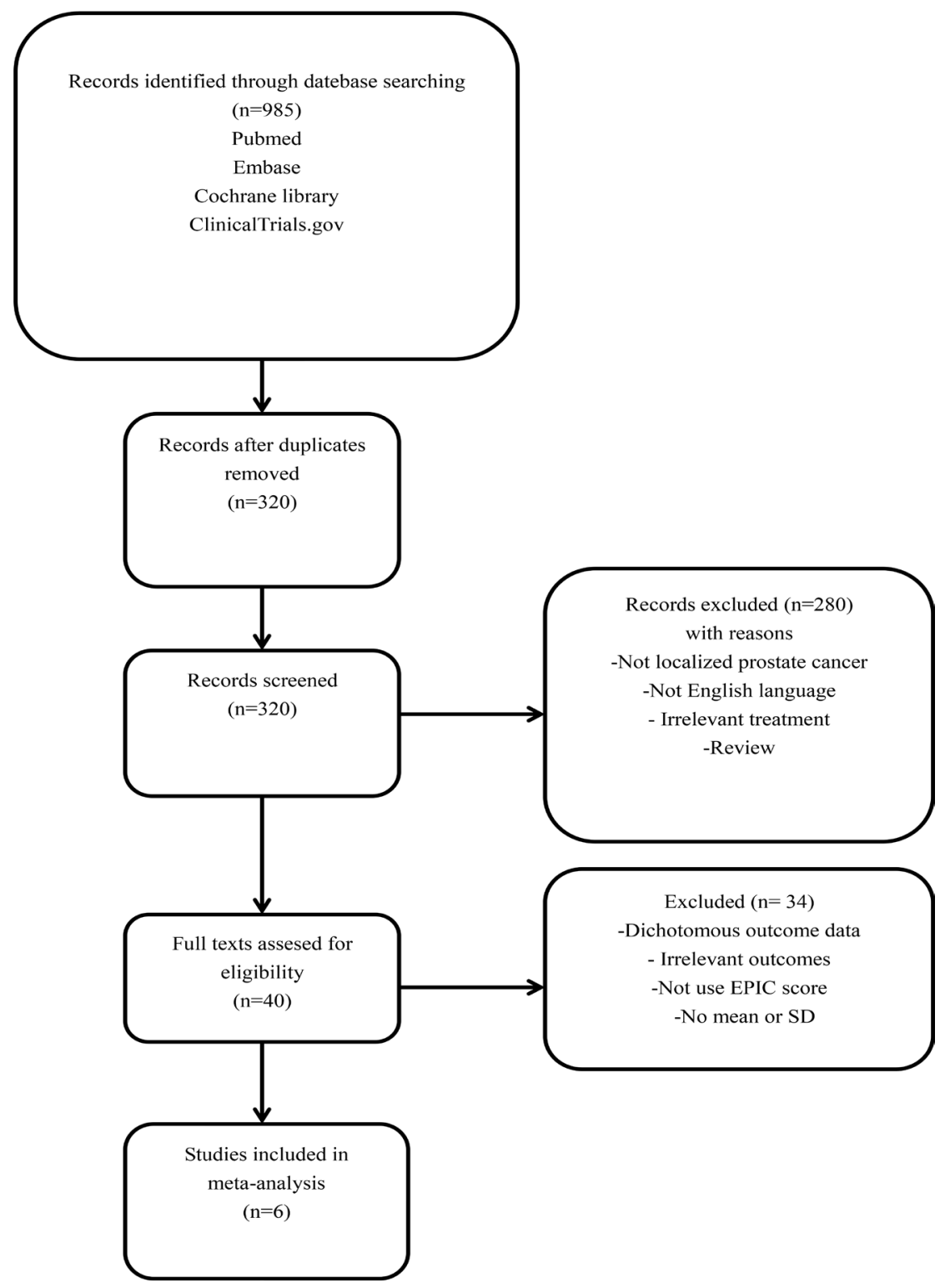

Figure 1: Flow chart illustrating the selection of studies for this meta-analysis. 
Table 1: Characteristics of studies included in this meta-analysis

\begin{tabular}{|c|c|c|c|c|c|c|c|}
\hline Study & Design & $\begin{array}{c}\text { QOL } \\
\text { measure }\end{array}$ & $\begin{array}{c}\text { Patient } \\
\text { numbers }\end{array}$ & Treatment cohorts & $\begin{array}{c}\text { QOL } \\
\text { domain }\end{array}$ & $\begin{array}{l}\text { NOS } \\
\text { score }\end{array}$ & Follow-up time \\
\hline Sanda 2008 & Prospective study & EPIC & $\begin{array}{l}\text { RP:603 } \\
\text { EBRT:292 }\end{array}$ & $\begin{array}{l}\text { RP: Retropubic, laparoscopic or } \\
\text { robot-assisted techniques with } \\
\text { nerve-sparing at the surgeon's } \\
\text { discretion } \\
\text { EBRT: Intensity-modulated } \\
\text { radiotherapy or highly conformal } \\
\text { techniques with ADT }\end{array}$ & $\begin{array}{l}\text { Sexual, } \\
\text { Bowel QOL }\end{array}$ & 7 & $2,6,12,24$ months \\
\hline Katz 2012 & $\begin{array}{l}\text { Retrospective } \\
\text { study }\end{array}$ & EPIC & $\begin{array}{l}\text { RP:123 } \\
\text { EBRT:216 }\end{array}$ & $\begin{array}{l}\text { RP: Retropubic prostatectomy } \\
\text { with nerve-sparing at the } \\
\text { surgeon's discretion } \\
\text { EBRT: } 35 \text { Gy in the first } 38 \\
\text { patients and } 36.25 \text { Gy in the } \\
\text { remaining without ADT }\end{array}$ & $\begin{array}{l}\text { Urinary, } \\
\text { Sexual, } \\
\text { Bowel QOL }\end{array}$ & 5 & $1,6,12,24,36$ months \\
\hline Ferrer 2008 & Prospective study & EPIC & $\begin{array}{l}\text { RP:134 } \\
\text { EBRT:205 }\end{array}$ & $\begin{array}{l}\text { RP: Retropubic prostatectomy } \\
\text { with nerve-sparing at the } \\
\text { surgeon's discretion } \\
\text { EBRT: 3D conformal technique }\end{array}$ & $\begin{array}{l}\text { Urinary, } \\
\text { Sexual, } \\
\text { Bowel QOL }\end{array}$ & 6 & $3,6,12,24$ months \\
\hline $\begin{array}{l}\text { Donovan } \\
2016\end{array}$ & RCT & EPIC & $\begin{array}{l}\text { RP:553 } \\
\text { EBRT:545 }\end{array}$ & $\begin{array}{l}\text { RP: Open retropubic, nerve- } \\
\text { sparing approach } \\
\text { EBRT: 3D conformal radiotherapy } \\
\text { at a total dose of } 74 \text { Gy with ADT }\end{array}$ & $\begin{array}{l}\text { Urinary, } \\
\text { Sexual, } \\
\text { Bowel QOL }\end{array}$ & 7 & $\begin{array}{l}6,12,24,36,48,60, \\
72 \text { months }\end{array}$ \\
\hline Resnick 2013 & Prospective study & EPIC & $\begin{array}{l}\text { RP:1164 } \\
\text { EBRT:491 }\end{array}$ & RP, EBRT & $\begin{array}{l}\text { Urinary, } \\
\text { Sexual, } \\
\text { Bowel QOL }\end{array}$ & 7 & $\begin{array}{l}6,12,24,60,180 \\
\text { months }\end{array}$ \\
\hline $\begin{array}{l}\text { Nicolaisen } \\
2014\end{array}$ & $\begin{array}{l}\text { Cross-sectional } \\
\text { survey }\end{array}$ & EPIC & $\begin{array}{l}\text { RP:38 } \\
\text { EBRT:59 }\end{array}$ & RP, EBRT & $\begin{array}{l}\text { Urinary, } \\
\text { Sexual, } \\
\text { Bowel QOL }\end{array}$ & 4 & 36 months \\
\hline
\end{tabular}

Abbreviations: RP, radical prostatectomy; EBRT, external beam radiation therapy; BT, brachytherapy; EPIC, Expanded Prostate Cancer Index Composite; QOL, quality of life; ADT, androgen deprivation therapy; NOS, Newcastle-Ottawa scale; RCT, randomized controlled trial.

second month (SMD $=-0.78 ; 95 \% \mathrm{CI}=-0.93$ to -0.63 ). The gap between RP and EBRT was diminished afterwards and got to the minimum difference in the fifth year (SMD $=-0.11 ; 95 \% \mathrm{CI}=-0.35$ to 0.14 ) (Supplementary Table 1). In the 15 th year, sexual quality of life was slightly better for RP than EBRT group $(\mathrm{SMD}=0.22 ; 95 \% \mathrm{CI}=$ 0.08 to 0.36 ) (Figure 5).

\section{Bowel quality of life}

Six studies [11-16] all reported bowel quality of life in the analysis, including 26 comparisons at different time points follow-up (Figure 4). Generally, patients undergoing RP had higher bowel domain scores than men undergoing EBRT (SMD $=0.42,95 \% \mathrm{CI}=0.33$ to 0.52 ) (Supplementary Table 1). In sub-group analysis, compare to EBRT group, RP group had the highest bowel domain scores in the first month $(\mathrm{SMD}=1.89 ; 95 \% \mathrm{CI}=1.57$ to 2.21) and experienced a sharp decrease in the second month $(\mathrm{SMD}=0.50 ; 95 \% \mathrm{CI}=0.35$ to 0.64$)$. The difference between RP and EBRT was shortening over the time and got to the minimum in the fifth year $(\mathrm{SMD}=0.17 ; 95 \%$ $\mathrm{CI}=-0.14$ to 0.47 ) (Supplementary Table 1 ). Afterwards, rebound happened in the sixth year $(\mathrm{SMD}=0.20 ; 95 \% \mathrm{CI}$ $=0.07$ to 0.33 ) and reached to a new peak in the 15 th year
$(\mathrm{SMD}=0.78 ; 95 \% \mathrm{CI}=0.64$ to 0.92$)$, indicating EBRT may have long-term bowel side effect (Figure 5).

\section{DISCUSSION}

Current standard therapies for clinically localized prostate cancer include RP and EBRT. RP is the standard option to treat localized prostate cancer; the open retropubic and minimally invasive surgical technique are used the most widely. EBRT utilizes an external source of radiation to treat the prostate gland for men with localized prostate cancer. Cancer-specific outcomes between EBRT and RP have been proven comparable by randomized controlled trial and observational data [17-19].

Disease-specific health-related outcomes regarding QOL are other essential components of decision making for men with prostate cancer [20-22]. Two papers published back-to-back in JAMA this year highlighted this issue. One study [23] proved RP was associated with a greater decrease in sexual function and more urinary incontinence than EBRT. In another study [24], sexual function in men decreased more markedly with RP than EBRT. EBRT was associated with acute worsening of urinary obstructive and bowel symptoms. The differences declined with time in these symptoms and had largely disappeared by 2 years. 
In the ProtecT trial, patient-reported QOL parameters were assessed for urinary, sexual, and bowel function [14], which results were in line with the above studies, showing worse urinary symptoms and sexual function related to surgery, and more bowel symptoms related to RT. Large literature had reported both short- and long-term functional outcomes after RP or RT for localized prostate cancer [15], [25-27]. A previous systematic review tried to provide clarity about QOL outcomes in receipt of RP and RT, but failed to make a meta-analysis [3]. After reviewing the relevant literature published so far, we found many studies report these functional outcomes only graphically. So we utilized computer software to take them out. As a result, data from six studies reporting health-related outcomes were pooled to complete this analysis.

Damage to the urinary sphincter can result in urinary incontinence following RP, particularly stress incontinence. In a multi-institution analysis that included 603 patients who had undergone RP, 52\% of patients reported urine leakage two months after surgery [11]. By 12 and 24 months, this had reduced to approximately $15 \%$. Roughly $7 \%$ continued to experience urinary symptoms at two years. During EBRT, approximately one half patient experienced urinary symptom. Several studies reported lower urinary tract side effects developed immediately post-EBRT [15, 16, 28-30], which mostly resolve within two years of treatment. However, Fransson [31] conducted a 15-year follow-up study and found that men had longterm urinary side effects of EBRT, which were stress and urge incontinence. So how sustained improvement in urinary function can be observed continues to be uncertain. One longitudinal study suggested that there was not any further improvement in the continence rate for men undergoing RP [32]. By contrast, another study proved prostate cancer patients with RP continue to recover urinary function after 12 month [33]. Our meta-analysis pooling EPIC domain urinary summary score proved urinary problems in patients undergoing RP developed most severely in the first month, dropped fast in the next two months and resolve constantly in the following 15 years. Both RP and EBRT group reached a comparable outcome regarding urinary QOL in the longterm. However, for the limitation of included studies, we cannot further compare the urinary function, bother, incontinence, irritation or obstruction situation to draw more exact conclusion.

In patients treated with RP and EBRT, sexual dysfunction occurred in most patients at two months and persisted after two years [11]. Larger-scale studies reported a higher incidence of sexual dysfunction in men treated with RP compared to EBRT $[28,34,35]$. We pooled EPIC domain sexual summary score to find out men treated

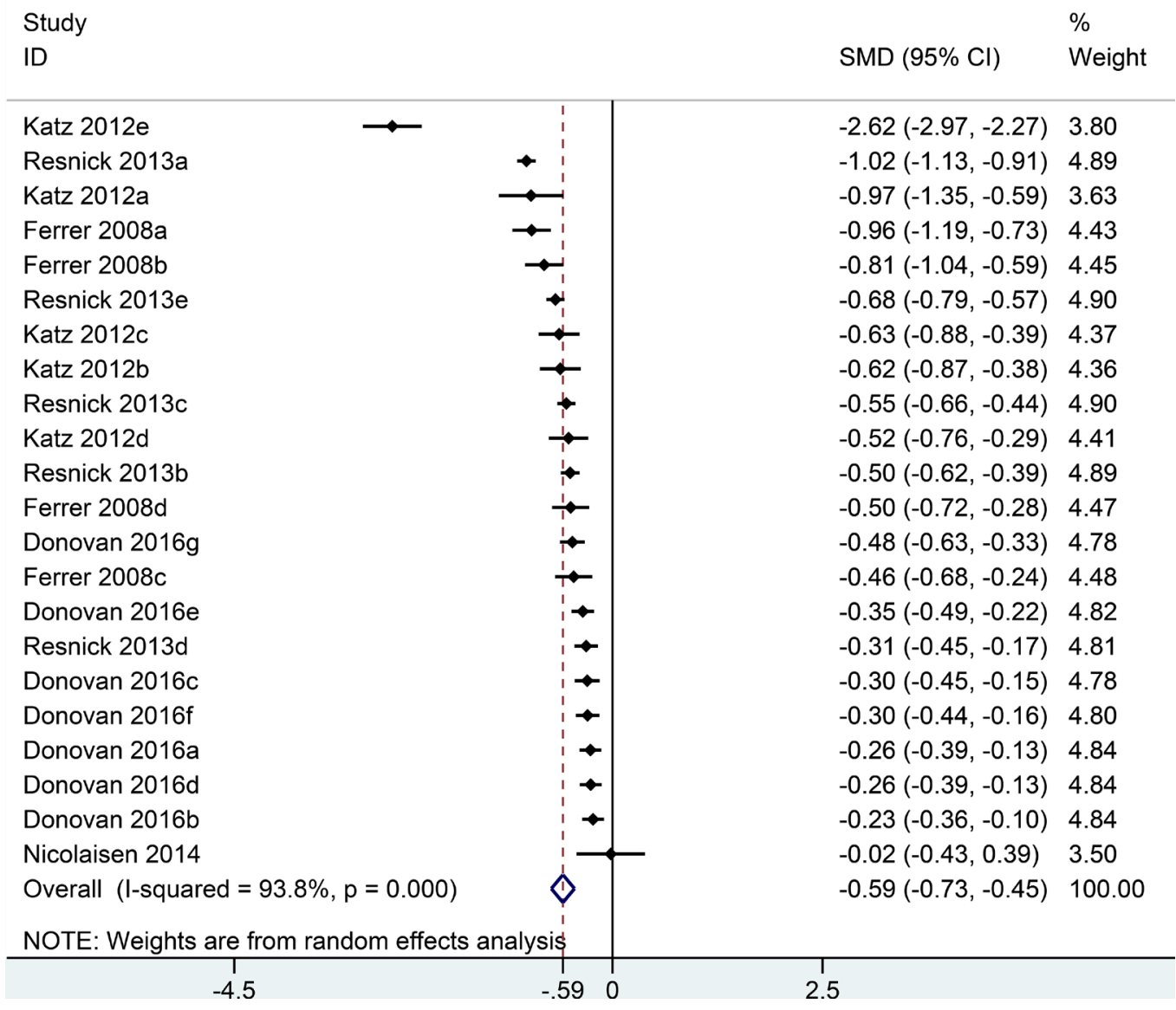

Figure 2: Forest plot showing urinary QOL of RP compared with EBRT. 
with RP experienced impaired sexual QOL immediately after surgery, which returned fast in the second month and improved over time. In the 15th year, sexual QOL was slightly worse in the EBRT group than RP, which may be caused by the use of adjuvant androgen-deprivation therapy [11]. For the same reason, sexual function or bother items cannot be made clear separately.

Bowel symptoms, primarily urgency and frequency, although rare after RP, were reported by $20 \%$ of patients treated with EBRT [11], which can be explained by the close proximity of prostate gland to the rectum, thus, the gastrointestinal tract getting the major toxicities of tissue irradiation. Most men treated with EBRT experienced short-term bowel dysfunction, mostly diarrhea, urgency, or abdominal or rectal pain. Acute symptoms usually resolve within two month [11]. Our analysis pooling EPIC domain bowel summary score also drew similar conclusion that EBRT group had the highest incidence of bowel side effects in the first month and resolve quickly within two month which can be controlled well in the subsequent five years. However, unlike other studies $[16,36]$, we found bowel symptoms deteriorated 5 years later especially in the 15th year, indicating EBRT may have long-term bowel side effect which cannot be ignored. Unfortunately, bowel function or bother problems cannot be ascertained further.

Some limitations exist in this analysis. First, significant heterogeneity was detected between studies of each domain which may be attributable to different study design, treatment and follow-up time. Second, only English papers were analyzed in our study, so the language bias may exist. Third, for the limited studies included, the funnel plot and publication bias were not presented and discussed. Forth, due to lacking sufficient data, other common treatment modalities for localized prostate cancer such as active surveillance, watchful waiting, and brachytherapy were not compared with RP and EBRT in this meta-analysis. Moreover, the financial burden between the two interventions for localized prostate cancer were not compared in this analysis, given increasing awareness on the cost influence in patients' decision making when choosing cancer treatments [37]. Finally, for the different versions or components of patient-reported outcome measures used,

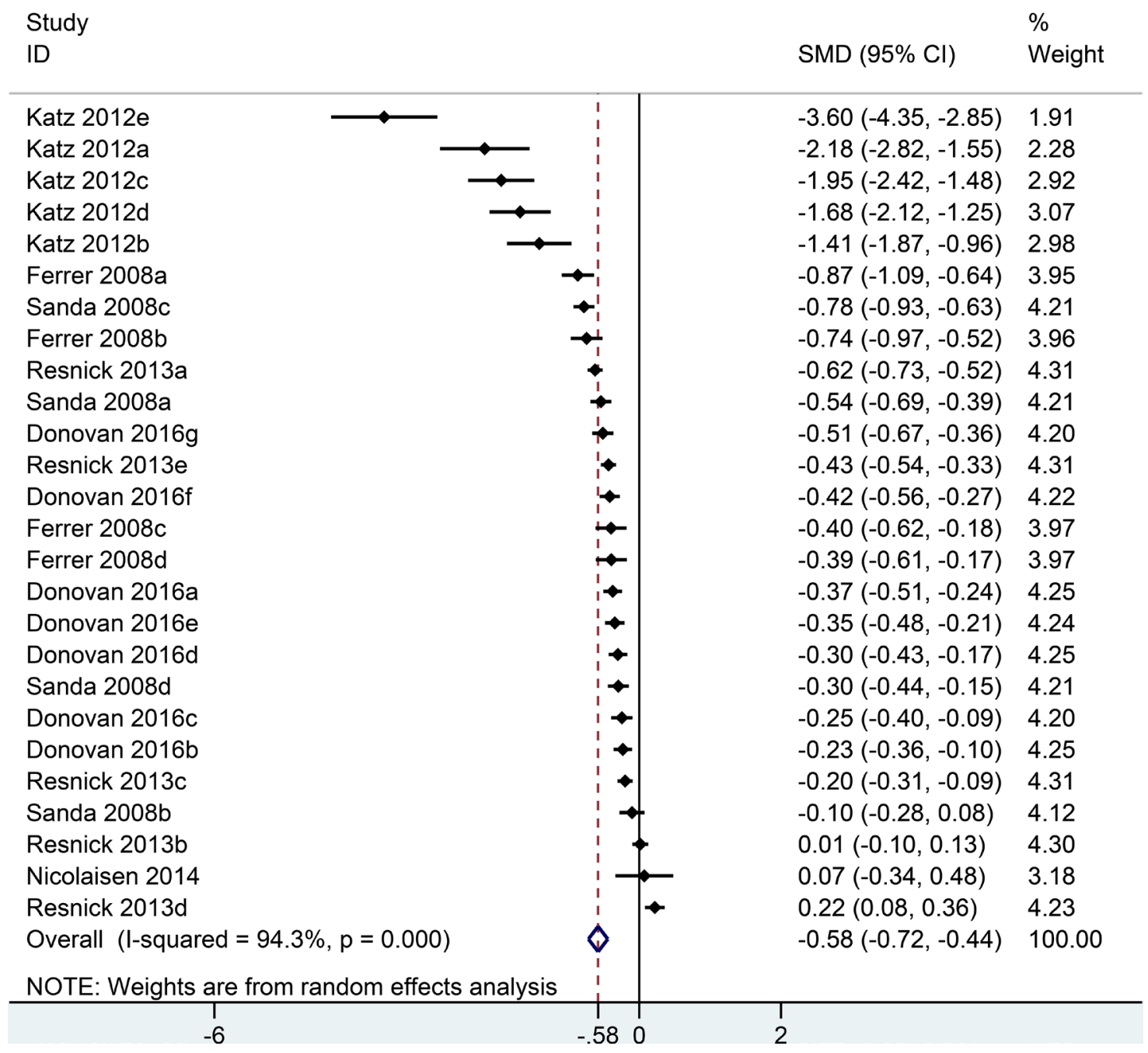

Figure 3: Forest plot showing sexual QOL of RP compared with EBRT. 


\begin{tabular}{|c|c|c|c|}
\hline \multicolumn{2}{|l|}{$\begin{array}{l}\text { Study } \\
\text { ID }\end{array}$} & \multirow{2}{*}{$\begin{array}{l}\text { SMD }(95 \% \mathrm{Cl}) \\
1.89(1.57,2.21)\end{array}$} & \multirow{2}{*}{$\begin{array}{l}\% \\
\text { Weight } \\
3.00\end{array}$} \\
\hline Katz 2012e & $\longrightarrow$ & & \\
\hline Resnick 2013d & $\rightarrow$ & $0.78(0.64,0.92)$ & 4.13 \\
\hline Resnick 2013a & $\rightarrow$ & $0.70(0.59,0.81)$ & 4.30 \\
\hline Katz 2012a & $\longrightarrow$ & $0.68(0.34,1.03)$ & 2.83 \\
\hline Donovan 2016c & $T^{1}$ & $0.51(0.36,0.66)$ & 4.09 \\
\hline Resnick 2013e & هـ & $0.50(0.40,0.61)$ & 4.30 \\
\hline Sanda $2008 c$ & $\frac{1}{1}-$ & $0.50(0.35,0.64)$ & 4.11 \\
\hline Katz 2012d & $\longrightarrow$ & $0.48(0.23,0.73)$ & 3.46 \\
\hline Donovan $2016 f$ & $\rightarrow$ & $0.42(0.28,0.56)$ & 4.14 \\
\hline Resnick $2013 c$ & & $0.41(0.31,0.52)$ & 4.30 \\
\hline Katz 2012b & -1 & $0.41(0.17,0.65)$ & 3.51 \\
\hline Katz 2012c & $\longrightarrow$ & $0.41(0.16,0.66)$ & 3.45 \\
\hline Sanda $2008 \mathrm{~b}$ & $\rightarrow$ & $0.35(0.17,0.53)$ & 3.91 \\
\hline Donovan $2016 \mathrm{~g}$ & لهم & $0.34(0.20,0.49)$ & 4.10 \\
\hline Donovan 2016b & $\rightarrow$ & $0.32(0.19,0.45)$ & 4.20 \\
\hline Ferrer 2008b & $\rightarrow$ & $0.32(0.10,0.54)$ & 3.66 \\
\hline Sanda 2008d & $\rightarrow 1$ & $0.31(0.16,0.46)$ & 4.10 \\
\hline Donovan $2016 e$ & $\rightarrow-1$ & $0.31(0.17,0.44)$ & 4.17 \\
\hline Ferrer $2008 c$ & $\rightarrow$ & $0.30(0.08,0.52)$ & 3.66 \\
\hline Sanda 2008a & $\rightarrow$ & $0.29(0.14,0.43)$ & 4.11 \\
\hline Ferrer 2008d & $\rightarrow 1$ & $0.25(0.03,0.47)$ & 3.66 \\
\hline Donovan 2016d & $\rightarrow$ & $0.25(0.12,0.38)$ & 4.19 \\
\hline Ferrer 2008a & $\rightarrow$ & $0.22(0.01,0.44)$ & 3.66 \\
\hline Donovan $2016 a$ & $\rightarrow 1$ & $0.20(0.07,0.33)$ & 4.20 \\
\hline Nicolaisen 2014 & & $0.08(-0.32,0.49)$ & 2.47 \\
\hline Resnick 2013b & & $0.01(-0.10,0.12)$ & 4.29 \\
\hline Overall $(I$-squared $=89.1 \%, p=0.000)$ & 今 & $0.42(0.33,0.52)$ & 100.00 \\
\hline \multicolumn{4}{|c|}{ NOTE: Weights are from random effects ahalyșis } \\
\hline \begin{tabular}{|c|}
1 \\
-2
\end{tabular} & 0.42 & & \\
\hline
\end{tabular}

Figure 4: Forest plot showing bowel QOL of RP compared with EBRT.

A

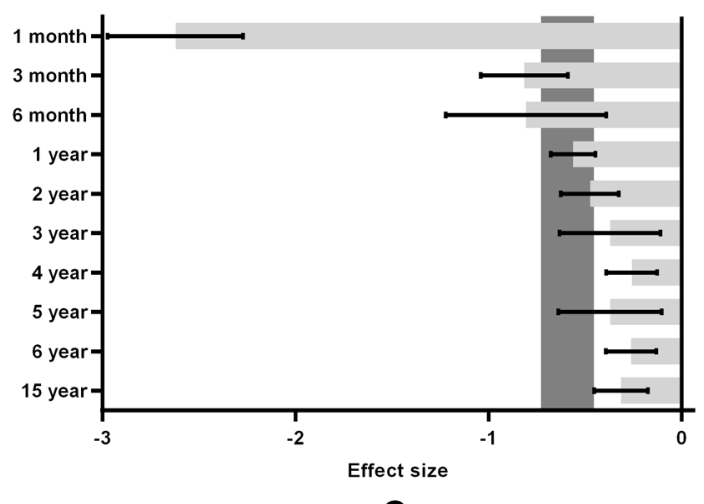

B

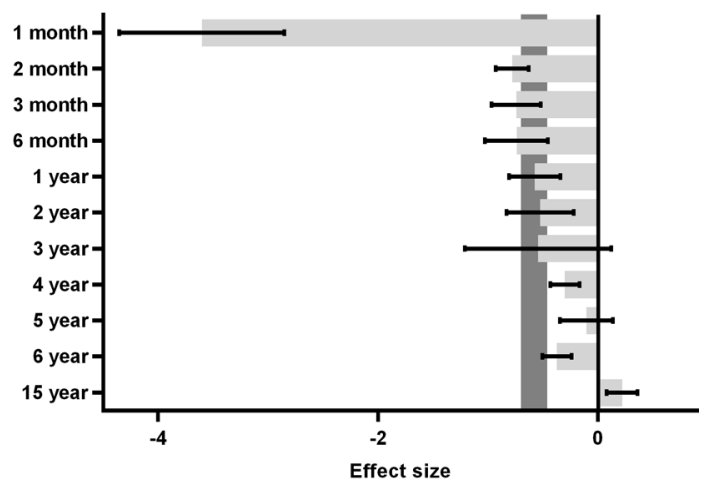

C

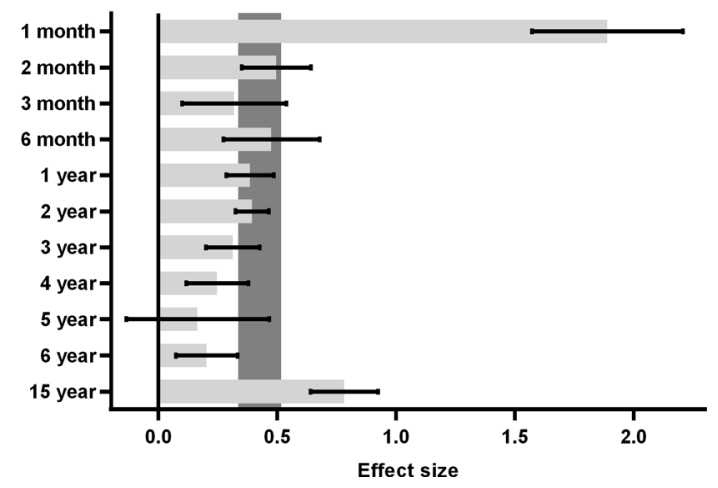

Figure 5: Sub-group analyses in urinary (A), sexual (B) and bowel (C) QOL stratified by follow-up time. 
many good studies cannot be include in this analysis and we are unable to compare EPIC sub-score of each specific domain as we mentioned above, specifically, function and bother items of urinary, sexual and bowel QOL.

In conclusion, men treated with RP experienced an acute worsen with respect to urinary and sexual QOL in the first two months post operation, which also happened in EBRT with bowel function. The two treatment groups continued to relieve in all functional outcomes to have similar health-related prognosis in the long-term followup. The future decision-making process must take into consideration of health-related outcomes during therapies for localized prostate cancer.

\section{MATERIALS AND METHODS}

\section{Selection criteria for relevant literature}

We conducted this analysis based on the Preferred Reporting Items for Systematic Reviews and MetaAnalyses (PRISMA) guidelines. Studies included met the criteria: (1) men diagnosed with localized prostate cancer. (2) treatment group is RP and EBRT. (2) outcome data were presented or can be calculated as mean and standard deviations (SD); (3) health-related QOL outcomes were presented as EPIC domain summary scores, specifically, urinary sum score, sexual sum score and bowel sum score. Each domain sub-score contained function and bother items. (4) the most recent or representative study of the same author or group was selected to include. Studies were excluded based on criteria: (1) no mean or SD values can be got; (2) not written in English; (3) not use EPIC score as QOL measurement tool.

\section{Literature search strategies and quality assessment}

English literature published before July 2017 was systematic searched in PubMed, EMBASE, the Cochrane Library and Web of Science using keywords: "Prostatic Neoplasms", "Patient Reported Outcome Measures", "quality of life", "sexual dysfunction", "urinary incontinence", "impotence", "bowel dysfunction", "prostatectomy", "radical prostatectomy", "radiotherapy" and "radiation therapy". The Newcastle-Ottawa scale was used to evaluate the quality of the included studies. Higher score means better methodology of studies. Literature quality was assessed by both authors (Chen $\mathrm{C}$ and Chen $\mathrm{Z}$ ) independently and disagreement was resolved through discussion.

\section{Data extraction}

Data such as patient demography, QOL measure, treatment cohorts, domains and follow-up time was obtained by two authors (Chen $\mathrm{C}$ and Wang K) independently. Mean and SD were extracted directly from the article or estimated from graphics using the GetData Graph Dizitizer. SD was recalculated from standard errors or $95 \%$ confidence interval (CI) when needed. Missing information was requested by mail from the first author or the corresponding author.

\section{Statistical analysis}

Stata 12.0 was used for statistical analysis and GraphPad Prism 6.0 was used to draw the bar chart in the sub-group analysis. Standardized mean difference (SMD) was used to compare continuous variables with the same domain. All results were described by $95 \% \mathrm{CI}$. Health-related QOL data are measured by EPIC in urinary, bowel, sexual domains in this analysis. A summary score constructed for each domain was collected, which range from 0 to 100 with high values indicate better functioning and quality of life. For comparison purposes, men treated with RP were set as the experimental group and men treated with EBRT were set as the control group. That is to say, an effect size $<0$ reflects worse QOL in men with RP and an effect size $>0$ reflects worse QOL in men with EBRT. Heterogeneity between studies was evaluated by Cochran's $Q$ test and $I^{2}$ test. Studies with $P<0.05$, $\mathrm{I}^{2}>50 \%$ were deemed heterogeneous, and was analysed by the random effect model. Sub-group analyses were conducted in urinary, bowel, sexual domains stratified by follow-up time points.

\section{Author contributions}

C. Chen and Z. Chen performed the literature research. C. Chen and K. Wang assessed the study quality. L.K. Hu and R. F. Xu made the statistical analysis. C. Chen drafed the manuscript. X.Z. He designed this study, and revised the manuscript.

\section{ACKNOWLEDGMENTS}

None.

\section{CONFLICTS OF INTEREST}

The authors declare no conflicts of interest.

\section{REFERENCES}

1. Mottet N, Bellmunt J, Bolla M, Briers E, Cumberbatch MG, De Santis M, Fossati N, Gross T, Henry AM, Joniau S, Lam TB, Mason MD, Matveev VB, et al. EAU-ESTROSIOG Guidelines on Prostate Cancer. Part 1: Screening, Diagnosis, and Local Treatment with Curative Intent. Eur Urol. 2017; 71:618-629.

2. Wei JT, Dunn RL, Litwin MS, Sandler HM, Sanda MG. Development and validation of the expanded prostate cancer 
index composite (EPIC) for comprehensive assessment of health-related quality of life in men with prostate cancer. Urology. 2000; 56:899-905.

3. Whiting PF, Moore TH, Jameson CM, Davies P, Rowlands MA, Burke M, Beynon R, Savovic J, Donovan JL. Symptomatic and quality-of-life outcomes after treatment for clinically localised prostate cancer: a systematic review. BJU Int. 2016; 118:193-204.

4. Schröder FH, Hugosson J, Roobol MJ, Tammela TL, Zappa M, Nelen V, Kwiatkowski M, Lujan M, Määttänen L, Lilja H, Denis LJ, Recker F, Paez A, et al. Screening and prostate cancer mortality: results of the European Randomised Study of Screening for Prostate Cancer (ERSPC) at 13 years of follow-up. Lancet. 2014; 384:2027-35.

5. Andriole GL, Crawford ED, Grubb RL 3rd, Buys SS, Chia D, Church TR, Fouad MN, Isaacs C, Kvale PA, Reding DJ, Weissfeld JL, Yokochi LA, O'Brien B, et al. Prostate cancer screening in the randomized Prostate, Lung, Colorectal, and Ovarian Cancer Screening Trial: mortality results after 13 years of follow-up. J Natl Cancer Inst. 2012; 104:125-32 .

6. Johansson E, Steineck G, Holmberg L, Johansson JE, Nyberg T, Ruutu M, Bill-Axelson A. Long-term qualityof-life outcomes after radical prostatectomy or watchful waiting:the Scandinavian Prostate Cancer Group-4 randomised trial. Lancet Oncol. 2011; 12:891-9.

7. Wilt TJ, Brawer MK, Barry MJ, Jones KM, Kwon Y, Gingrich JR, Aronson WJ, Nsouli I, Iyer P, Cartagena R, Snider G, Roehrborn C, Fox S. The Prostate cancer Intervention Versus Observation Trial:VA/NCI/AHRQ Cooperative Studies Program \#407 (PIVOT):design and baseline results of a randomized controlled trial comparing radical prostatectomy to watchful waiting for men with clinically localized prostate cancer. Contemp Clin Trials. 2009; 30:81-7.

8. Wilt TJ, MacDonald R, Rutks I, Shamliyan TA, Taylor BC, Kane RL. Systematic review: comparative effectiveness and harms of treatments for clinically localized prostate cancer. Ann Intern Med. 2008; 148:435-48.

9. Chou R, Croswell JM, Dana T, Bougatsos C, Blazina I, Fu R, Gleitsmann K, Koenig HC, Lam C, Maltz A, Rugge JB, Lin K. Screening for prostate cancer: a review of the evidence for the U.S. Preventive Services Task Force. Ann Intern Med. 2011; 155:762-71.

10. Wallis CJ, Saskin R, Choo R, Herschorn S, Kodama RT, Satkunasivam R, Shah PS, Danjoux C, Nam RK. Surgery Versus Radiotherapy for Clinically-localized Prostate Cancer: A Systematic Review and Meta-analysis. Eur Urol. 2016; 70:21-30.

11. Sanda MG, Dunn RL, Michalski J, Sandler HM, Northouse L, Hembroff L, Lin X, Greenfield TK, Litwin MS, Saigal CS, Mahadevan A, Klein E, Kibel A, et al. Quality of life and satisfaction with outcome among prostate-cancer survivors. N Engl J Med. 2008; 358:1250-61.

12. Katz A, Ferrer M, Suárez JF. Comparison of quality of life after stereotactic body radiotherapy and surgery for earlystage prostate cancer. Radiat Oncol. 2012; 7:194.
13. Ferrer M, Suárez JF, Guedea F, Fernández P, Macías V, Mariño A, Hervas A, Herruzo I, Ortiz MJ, Villavicencio H, Craven-Bratle J, Garin O, Aguiló F, et al. Healthrelated quality of life 2 years after treatment with radical prostatectomy, prostate brachytherapy, or external beam radiotherapy in patients with clinically localized prostate cancer. Int J Radiat Oncol Biol Phys. 2008; 72:421-32.

14. Donovan JL, Hamdy FC, Lane JA, Mason M, Metcalfe C, Walsh E, Blazeby JM, Peters TJ, Holding P, Bonnington S, Lennon T, Bradshaw L, Cooper D, et al. Patient-Reported Outcomes after Monitoring, Surgery, or Radiotherapy for Prostate Cancer. N Engl J Med. 2016; 375:1425-1437.

15. Resnick MJ, Koyama T, Fan KH, Albertsen PC, Goodman M, Hamilton AS, Hoffman RM, Potosky AL, Stanford JL, Stroup AM, Van Horn RL, Penson DF. Long-term functional outcomes after treatment for localized prostate cancer. N Engl J Med. 2013; 368:436-45.

16. Nicolaisen M, Müller S, Patel HR, Hanssen TA. Quality of life and satisfaction with information after radical prostatectomy, radical external beam radiotherapy and postoperative radiotherapy:a long-term follow-up study. J Clin Nurs. 2014; 23:3403-14.

17. Roach M, Ceron LT, Lazar AA. Radical Prostatectomy Versus Radiation and Androgen Deprivation Therapy for Clinically Localized Prostate Cancer:How Good Is the Evidence. Int J Radiat Oncol Biol Phys. 2015; 93:1064-70.

18. Hamdy FC, Donovan JL, Lane JA, Mason M, Metcalfe C, Holding P, Davis M, Peters TJ, Turner EL, Martin RM, Oxley J, Robinson M, Staffurth J, et al. 10-Year Outcomes after Monitoring, Surgery, or Radiotherapy for Localized Prostate Cancer. N Engl J Med. 2016; 375:1415-1424.

19. Lennernäs B, Majumder K, Damber JE, Albertsson P, Holmberg E, Brandberg Y, Isacsson U, Ljung G, Damm $\mathrm{O}$, Nilsson S. Radical prostatectomy versus high-dose irradiation in localized/locally advanced prostate cancer:A Swedish multicenter randomized trial with patient-reported outcomes. Acta Oncol. 2015; 54:875-81.

20. Ihrig A, Keller M, Hartmann M, Debus J, Pfitzenmaier J, Hadaschik B, Hohenfellner M, Herzog W, Huber J. Treatment decision-making in localized prostate cancer:why patients chose either radical prostatectomy or external beam radiation therapy. BJU Int. 2011; 108:1274-8.

21. Sommers BD, Beard CJ, D’Amico AV, Kaplan I, Richie JP, Zeckhauser RJ. Predictors of patient preferences and treatment choices for localized prostate cancer. Cancer. 2008; 113:2058-67.

22. Fleming C, Wasson JH, Albertsen PC, Barry MJ, Wennberg JE. A decision analysis of alternative treatment strategies for clinically localized prostate cancer. Prostate Patient Outcomes Research Team. JAMA. 1993; 269:2650-8.

23. Barocas DA, Alvarez J, Resnick MJ, Koyama T, Hoffman KE, Tyson MD, Conwill R, McCollum D, Cooperberg MR, Goodman M, Greenfield S, Hamilton AS, Hashibe M, et al. Association Between Radiation Therapy, Surgery, or Observation for Localized Prostate Cancer and 
Patient-Reported Outcomes After 3 Years. JAMA. 2017; 317:1126-1140.

24. Chen RC, Basak R, Meyer AM, Kuo TM, Carpenter WR, Agans RP, Broughman JR, Reeve BB, Nielsen ME, Usinger DS, Spearman KC, Walden S, Kaleel D, et al. Association Between Choice of Radical Prostatectomy, External Beam Radiotherapy, Brachytherapy, or Active Surveillance and Patient-Reported Quality of Life Among Men With Localized Prostate Cancer. JAMA. 2017; 317:1141-1150.

25. Potosky AL, Harlan LC, Stanford JL, Gilliland FD, Hamilton AS, Albertsen PC, Eley JW, Liff JM, Deapen D, Stephenson RA, Legler J, Ferrans CE, Talcott JA, et al. Prostate cancer practice patterns and quality of life:the Prostate Cancer Outcomes Study. J Natl Cancer Inst. 1999; 91:1719-24.

26. Potosky AL, Legler J, Albertsen PC, Stanford JL, Gilliland FD, Hamilton AS, Eley JW, Stephenson RA, Harlan LC. Health outcomes after prostatectomy or radiotherapy for prostate cancer:results from the Prostate Cancer Outcomes Study. J Natl Cancer Inst. 2000; 92:1582-92.

27. Potosky AL, Davis WW, Hoffman RM, Stanford JL, Stephenson RA, Penson DF, Harlan LC. Five-year outcomes after prostatectomy or radiotherapy for prostate cancer:the prostate cancer outcomes study. J Natl Cancer Inst. 2004; 96:1358-67.

28. Clark JA, Talcott JA. Symptom indexes to assess outcomes of treatment for early prostate cancer. Med Care. 2001; 39:1118-30.

29. Fulmer BR, Bissonette EA, Petroni GR, Theodorescu D. Prospective assessment of voiding and sexual function after treatment for localized prostate carcinoma:comparison of radical prostatectomy to hormonobrachytherapy with and without external beam radiotherapy. Cancer. 2001; 91:2046-55.

30. Lilleby W, Fosså SD, Waehre HR, Olsen DR. Long-term morbidity and quality of life in patients with localized prostate cancer undergoing definitive radiotherapy or radical prostatectomy. Int J Radiat Oncol Biol Phys. 1999; 43:735-43.

31. Fransson P. Patient-reported lower urinary tract symptoms, urinary incontinence, and quality of life after external beam radiotherapy for localized prostate cancer-15 years' follow-up. A comparison with age-matched controls. Acta Oncol. 2008; 47:852-61.

32. Prabhu V, Sivarajan G, Taksler GB, Laze J, Lepor H. Long-term continence outcomes in men undergoing radical prostatectomy for clinically localized prostate cancer. Eur Urol. 2014; 65:52-7.

33. Lee JK, Assel M, Thong AE, Sjoberg DD, Mulhall JP, Sandhu J, Vickers AJ, Ehdaie B. Unexpected Long-term Improvements in Urinary and Erectile Function in a Large Cohort of Men with Self-reported Outcomes Following Radical Prostatectomy. Eur Urol. 2015; 68:899-905.

34. Madalinska JB, Essink-Bot ML, de Koning HJ, Kirkels WJ, van der Maas PJ, Schröder FH. Health-related qualityof-life effects of radical prostatectomy and primary radiotherapy for screen-detected or clinically diagnosed localized prostate cancer. J Clin Oncol. 2001; 19:1619-28.

35. Pardo Y, Guedea F, Aguiló F, Fernández P, Macías V, Mariño A, Hervás A, Herruzo I, Ortiz MJ, Ponce de León J, Craven-Bratle J, Suárez JF, Boladeras A, et al. Qualityof-life impact of primary treatments for localized prostate cancer in patients without hormonal treatment. J Clin Oncol. 2010; 28:4687-96.

36. Miller DC, Sanda MG, Dunn RL, Montie JE, Pimentel H, Sandler HM, McLaughlin WP, Wei JT. Long-term outcomes among localized prostate cancer survivors:health-related quality-of-life changes after radical prostatectomy, external radiation, and brachytherapy. J Clin Oncol. 2005; 23:2772-80.

37. Jiang CC, Fraenkel L. The Influence of Varying Cost Formats on Preferences. Med Decis Making. 2017; 37:17-26. 